\title{
The problem of the sign in philosophy of postmodernism
}

\author{
Victor Novoselov \\ Department of Philosophy, Novosibirsk State Technical University, Novosibirsk, Russia \\ Email address: \\ viktor-novoselov@yandex.ru
}

To cite this article:

Victor Novoselov. The Problem of the Sign in Philosophy of Postmodernism. International Journal of Philosophy. Vol. 2, No. 3, 2014, pp. 31-35. doi: 10.11648/j.ijp.20140203.11

\begin{abstract}
Given article is devoted to the analysis of a problem of a sign essence in postmodernism philosophy on an example of Deleuze book "The logic of sense». Deleuze except the concepts accepted in a classical paradigm "denotation" and "meaning" enters one more concept of sense which does not merge with the proposition, nor with a state of affairs, designates which given offer. He leans on 4 element structure of a sign: expression, denotation, signification and sense. Deleuze uses this concept to challenge existing philosophical concepts of signification and to bypass the restrictions imposed by the representative theory of a sign.
\end{abstract}

Keywords: Expression, Denotation, Signification, Manifestation, Sense, Designation

\section{Introduction}

The traditional structure of a sign is based on the theory of representation, i.e. on a postulate that a sign represent any phenomenon or a subject, forming, thus, figurative structure: meaning, meant and the referent [2-9].

That is, actually a sign - in a natural language a word, written or oral, concept - its semantic maintenance (in different languages the same maintenance can be expressed differently), and a real subject or the phenomenon which is taking place in the extra language validity.

In postmodernist philosophy the sign theory is exposed to the most radical revaluation.

Deleuze, being based on a classical paradigm, allocates three different relations in the offer. It is accepted to name the first denotation [designation] or indication [instructions]. It speaks about the relation of the offer to an external state of affairs (datum). It includes those or other bodies, mixtures of bodies, qualities, quantities and communications. Designation procedure consists in connection of words with concrete images which should "represent" a state of affairs: from all images, associated with a word - with that or other word in the offer, - it is necessary to select, allocate that correspond to this complex. The designating intuition is expressed in shape: "it is that", "it - not that". [1, p.29]

\section{Three Relations of the Proposition}

Deleuze notices that separate words in the proposition, in general all linguistic components always play a role of empty forms for selection of images and, hence, for a designation of any state of affairs. It is not necessary to consider such words as universal concepts as they are only formal singularities functioning as pure "index". As examples of such formal indicators words can serve: here, it, that, here, there, yesterday, now etc. Own names also are indicators - indexes. But their role is special as only they form material singularities as those. From the logic point of view, as criterion and an element of denotation its validity or lie acts. "True" means or that the state of affairs effectively fills corresponding denotation or those indexes "are realized" or that the image is picked correctly up." Truly in all cases "means that all infinite series of the concrete images connected to words is filled, and thus any selection any more it is not required. «Lie» means that denotation is not filled or because of any defect of selected images, or because of basic impossibility to create an image united with words. Thus, denotation it will quite be co-ordinated with the concept entered by Frege.

The second relation of the proposition Deleuze names manifestation. This relation consists in communication between the offer and the subject who speaks and expresses itself. Hence, demonstration is represented as the statement of desire or the belief, corresponding to the offer. The desire and belief are causal conclusions, instead of associations. The desire is internal causality an image, concerning existence of object or corresponding state of affairs.

Accordingly, the belief is an anticipation of object or a 
state of affairs which existence should be set external causality. From here does not follow that manifestation is secondary in the relation of denotation. On the contrary, thanks to it denotation in general becomes possible, and conclusions provide the regular unity generating associations [of words and things]. Primacy of demonstration is proved and by means of the linguistic analysis allocating in the offer specific "demonstrating" particles of type: I, you, tomorrow, always, somewhere, everywhere etc. Just as own name am the exclusive indicator, "I" - the basic manifestater. But from I depend not only all other manifestaters, all indicators also are connected with it also. Indication, or a designation, corresponds with the individual states of affairs, separate images and the individual designating. Manifestaters, since "I", set area personal, operating as a principle of all possible denotations. At last, at transition from denotation to demonstration there is a displacement of logic values that is shown by means of such instance, as Cogito: speech goes now not about true or lie, and about reliability or illusion. [1, p.33-34]

To the third relation of the proposition of Deleuze fixes name «signification». Here it is a question of communication of a word with universal or general concepts and about the relation of syntactic links to that is concluded in concept. From the point of view of signification offer elements represent "meaning" the conceptual maintenances, capable to send to other offers which, in turn, represent itself as preconditions of the given offer. Signification it is defined by these order conceptual implications where the considered offer is entered only as "a proof" element in the most general sense of a word: either as a parcel, or as the conclusion. Thus, "comprises" and "hence" is, in essence, linguistic meaning. Implication - a sign defining the relation between parcels and the conclusion;" Hence "- the sign on judgment setting possibility of the statement as a conclusion from this that is concluded in concept. [1, p.35-36]

Thus, «signification» at Deleuze has the same value, as "meaning" at Frege and Russell [2, 3].

When Deleuze speaks about the proof in the most general sense means the following: value of the proposition is always found out by means of indirect procedure corresponding to it, through its communications with other offers from which it is deduced or, on the contrary, which can be deduced from it. On the contrary, denotation specifies in direct action.

According to Deleuze, the proof should understand neither in narrow syllogistic, nor in mathematical, neither in physical likelihood senses, nor in moral sense of promises and obligations. In the latter case removal of judgment of the conclusion also is real execution of the promised. A logic estimation understood thus signification and proofs is now not the true (to what the hypothetical kind of implication testifies), and a true condition - set of conditions at which the offer "would be" true. The caused, deduced offer happens false in case specifies in a nonexistent state of affairs or when cannot be verified directly. Signification does not cause the validity [offer] without thereby not to set and error possibilities. Therefore validity conditions resist not to lie, and absurdity, that is that exists without value, or that can be neither true, nor lie.

\section{What is Primary: Denotation, Signification or Manifestation}

On a question on, whether it is primary signification in relation to manifestation and denotation, Deleuze gives the developed answer. So, for example, if demonstration is primary concerning designation and it is basis, that only from very specific point of view. Resorting to classical distinction, we say that manifestation is primary from the point of view of speech even if it is silent speech. At speech level I begin and begin absolutely. Hence, as speech I initially not only concerning all possible denotations for which it forms the basis, but also concerning all significations which it covers. But from this point of view conceptual signification neither are self-sufficient, nor are opened as those: they only are meant I, considering as having such value which is understood at once and coincides with own manifestation.

Thus, according to Deleuze, superiority of manifestation in the relation not only denotation, but also signification should be understood only as "speech" where values naturally contain implicate. But whether there is no other order where values are self-sufficient and opened as those? In it they would be primary and would lie at the heart of manifestation. Such order is, and it is a language order. Here the offer can act only as the precondition or a conclusion and as meaning concepts to manifestation the subject and even to a designation of a state of affairs. [1, p.35-36]

In the same way desires would not set any order of requirements and the duties, distinct from ordinary pressing needs; and beliefs would not set the order of conclusions which is distinct from simple opinions if words in which they are demonstrated, did not send first of all to concepts, to conceptual implications, to giving these desires and beliefs the importance.

However, considers Deleuze, prospective superiority signification over denotation lifts one more delicate problem. When we speak "hence" when we consider the offer as a conclusion, we do by its object of the statement. It means that we lay aside parcels and we confirm the offer in itself, irrespective of them. We connect the offer with a state of affairs in which it specifies, irrespective of implication, establishing its value. But for this purpose it is necessary to satisfy two conditions. It is necessary, that preconditions were really true. So, we are compelled to depart from a pure order of implication to connect preconditions with the designated state of affairs assumed by us. But even if to consider that preconditions and in are true, it is possible to deduce from them only that offer about which there is a speech (we name it Z). It is necessary to separate only it from these preconditions and to confirm in itself, irrespective of conclusion procedure, lowering that $\mathrm{Z}$, in turn, 
truly, time is true A and B. And it is equivalent to the offer C, remaining in procedure of a conclusion and not capable it to come off, as $\mathrm{C}$ sends to offer $\mathrm{D}$ asserting that " $\mathrm{Z}$ is true, if are true A, B and C.", and so indefinitely. More shortly, the conclusion can be separated from preconditions but only provided that other preconditions, from which the conclusion just and inseparably are always added. All it allows to tell that signification never happens homogeneous, and two signs - "implicate" and "hence" - are completely diverse, and that conclusion procedure never proves denotation for last is already executed: once in preconditions and at times in the conclusion. [1, p.37]

So, according to Deleuze, from denotation through manifestation to signification and back - from signification through manifestation to denotation - us attracts on a circle which makes an offer circle. Further Deleuze asks a question: whether «we should be limited to these three relations of the offer, or it is necessary to add the fourth which would be sense? $»[1$, p. 37].

Thus, Deleuze enters one more concept of sense. He considers that it is not so necessary to build certain a posteriorly model corresponding to the above-stated relations. More likely the model should work a priori from within, time it compels to enter the additional relation which cannot be identified on experience from the outside. " At first it is necessary to ask: whether it is possible to localize sense in one of the given three relations - denotation, demonstration or signification? At once it is possible to answer that such localization, apparently, is impossible inside denotation. Executed denotation sets the validity of the offer, outstanding - lie. It is obvious that the sense cannot consist that proposes marriage true or false.

There cannot be it and the relation where such estimations are realized. Moreover, denotation could support offer weight only in that degree in what conformity between words and the designated things or states of affairs is traced. What then remains, what will protect us from an arbitrariness denotation to which corresponds nothing, from emptiness of indexes, that is formal meaning type "it" - if both that and another will appear deprived of sense? All designations necessarily assume sense, and we inevitably appear at once in sense every time when something we designate $\gg .[1, \mathrm{p} .38]$

\section{The Fourth Relation of the Proposition}

Will be more chances of success, considers Deleuze if to identify sense with manifestation for the designating make sense only thanking I, demonstrating in the offer. I am really initially as allows speech to begin. From here a conclusion: the sense stays in beliefs (or desires) the one who express itself. However, we have seen that the order of beliefs and desires is based on an order conceptual implication of values, and that I which speaks or say identity "I", is guaranteed only by a continuity certain meant (concepts of God, the world...). I am initially and self-sufficiently as speech as turns off values which should be developed as language. If these values collapse, if they do not possess internal stability, personal identity is lost. That is why last possibility, apparently, consists in identifying sense with signification. $[1, \mathrm{p} .37]$

It is not excluded, considers Deleuze that there is an even more general reason because of which value suffers failure and because of which the basis and proved are closed in a cycle. When we define signification as a true condition, we give it the characteristic which it divides with sense and which already is the sense characteristic. But how signification finds this characteristic? How it uses it? Discussing validity conditions, we thereby have towered over true and lie as the false offer too makes sense also value. But at the same time, we define this higher condition only as possibility for the offer to be true. Such possibility for the offer to be true - that other, as the form of possibility of the offer as that. There are many forms of possibility for offers: logic, geometrical, algebraic, physical, and syntactic. Aristotle has defined the logic form of possibility through communication between terms of the offer and "places", concerning accidents, properties, sorts and definitions. And Kant has thought up even two new forms of possibility transcendental and moral. But as though we defined the possibility form, procedure of such definition has additional character as includes ascension from caused to a condition which is thought thus as simple possibility of the caused. Here we go back to the basis. But that is proved, remains to the same, than and was, irrespective of procedure proving it.

Last does not influence for that is proved. Thus, denotation there is external to that order which causes it, and a true and lie - are indifferent to a principle defining possibility true or false that allows them to remain in the former relation to each other. Caused always sends to a condition, and a condition - to cause. To a condition of true to avoid the same defect, it should possess own element which would differ from the form of the caused. That is in it there should be something unconditional, capable to provide real genesis of denotation and other relations of the offer. Then the true condition could be defined any more as the form of conceptual possibility, and as a certain ideal matter or ideal "layer", that is not as signification, and as sense. [1, p.38]

Thus, Deleuze considers that the sense is the fourth relation of the proposition. For a substantiation of it he leans against marginal philosophical tradition (stoicism) and on experiences of art and literary Avant-guard. He considers that stoics have opened sense together with event: the sense expressed, in the offer is incorporeal, difficult and not reduced to what to other essence on a surface of things; the pure event inherent in the offer and living in it.

Deleuze considers that such historical dating is not casual. According to Deleuze, a question here in what: whether there is something such, what does not merge neither with offers, nor with its terms, with object, or a state of affairs designated by the offer, with "live", whether it be representation or mental activity of the one who expresses 
itself in the offer, with concepts or even with meant essences? If is, sense, or that is expressed by the offer, is not reduced to individual states of affairs, concrete images, personal beliefs and universal or general concepts. Stoics have generalized it: neither a word, nor a body, neither sensual representation, nor rational representation. And it is better so: Probably, the sense is something "neutral", to fit the general is entirely indifferent as specific, and, both individual, and universal, both personal, and impersonal. Thus the sense possesses absolutely other nature.

Deleuze asks a question: «But whether it is necessary to recognize existence of such additional instance? Or we should manage somehow that already we have: denotation, manifestation and signification? Disputes about it arise again and again. It is difficult to answer those who have enough words, things, images and ideas. For it is impossible even to tell, whether is a sense in things or in reason. At it is not present either physical or mental existence. Whether we can tell, at least, that it is useful, what it needs to be admitted from utilitarian reasons? No as it is allocated invalid, passionless, sterile shine. That is why we have told that we can to judge indirectly only, actually, it on the basis of that circle on which we are conducted by usual relations of the offer.

Only breaking off a circle, developing and untwisting it like Mobius's tape, we find out the sense relation as that, appearing before us in all the non-reducing and genetic force thanks to which the aprioristic internal model of the offer revives. The logic of sense is inspired by spirit of empiricism. Only the empiricism knows how to fall outside the limits visibilities of experience, without being taken prisoner Ideas and how to track down, catch, conclude, and can be and most to cause the phantom on border of the experience continued and developed to a limit ». [1, p.38]

Further Deleuze addresses to phenomenology of Husserl. « Husserl names this limiting relation expression. It separates the last from a designation, demonstration and the proof. The sense is that is expressed. Husserl in not smaller degree, than Mainong, it was possible to touch anew a live source of inspiration by Stoics. So, for example, when Husserl reflects apropos «perception noema or "sense of perception", it from the very beginning distinguishes them from physical objects, from all psychological, or vital, from mental representations and from logic concepts. It describes noema as the passionless and incorporeal essence deprived of physical or mental existence which neither operates, nor is exposed to influence, - pure result, or pure "phenomenon". The real tree (denotat) can be burnt; it can be the subject and object of actions and to enter into mixes of bodies. However anything similar it is impossible to tell about noema "tree". At same denotat can be much noema and senses: The evening star and morning star are two noema that is two ways with what same denotat can be presented in expression. Means, when Husserl says that the poem is apprehended as it is in representation, "apprehended as that", or the phenomenon it is not necessary to understand it so as if noema something bears in itself sensually given, or quality.
On the contrary, it bears in herself ideal objective unity as intentional correlate the perception certificate. Noema it is not given in perception (as it is not given in memoirs or an image). At it absolutely other status consisting in nonexistence out of the offer expressing it - whether it be judgment of perception or imagination, memoirs or representation ». [1, p.39]

Further Deleuze considers the difficult status of sense or that is expressed. On the one hand, the sense does not exist out of the offer expressing it. That is expressed, does not exist out of the expression. "That is why we cannot tell that the sense exists, but that he, more likely, persists or lives. That is expressed, is not similar to something in expression. Really, sense - that is given as attribute, but it at all attribute of the offer, more likely, it attribute of a thing or a state of affairs».

The attribute of the proposition is a predicate, a qualitative predicate like "green", for example. It is attributed as attribute to the subject of the offer. But as attribute of a thing the verb serves: to turn green, for example, or, better, the event expressed by this verb. It is attributed as attribute of that thing in which the subject, or to that state of affairs which is designated by all offer specifies.

«On the contrary, the logic attribute does not merge at all neither with a physical state of affairs, nor with its quality or the relation. Attribute - not life. It does not define life. It super-life. «Green» designates quality, a mix of things, a tree and air mix when the chlorophyll co-exists with all parts of sheet. On the contrary, «to turn green»- is not quality of a thing, and attribute which expresses a thing. The attribute does not exist out of the offer which expresses it, designating a thing. Here we come back to with what have begun: the sense does not exist out of the offer... And so on.

But it is not a circle. It is, more likely, such coexistence of two parties of one deprived thickness of a plane that we get on the one hand on another, moving ahead lengthways their lengths ». [1, p.40]

\section{Conclusions}

Thus, Deleuze except the concepts accepted in a classical paradigm "denotation" and "sense" (meaning, signification) enters one more concept of sense which does not merge with the offer, or with a state of affairs or the quality, designates which given offer. It is border between offers and things. «It is that a liquid which possesses at once both super-life, and persistence, that is that minimum of life which induces persistence. For this reason the sense also is" event "provided that event does not mix up with the existential realization in a state of affairs. So we will not ask now, in what sense of event: event also is sense as that. Event on the essence belongs to language. It has the essential relation to language. But language is that expresses things». [1, s.40-41]

Thus, according to Deleuze, the sense is and expressed, that is expressed by the offer, and attribute of a state of affairs. It is developed one party to things, and another - to propositions. 


\section{References}

[1] G. Deleuze. The Logic of Sense. - Columbia University Press, 1990.

[2] Russell B. On Denoting //The Philosophy of Language (3 edition), A. P. Martinich (ed.). - Oxford University Press, 1996. P. $112-126$.

[3] The Frege Reader, ed. M. Beaney, Oxford: Basil Blackwell. 1997.

[4] Davidson D. Truth and Meaning. - Synthesis, 17 (1967). Pp. 304-323.

[5] Davidson D. Radical Interpretation. - Dialectica, 27 (1973). Pp. 313-327.

[6] Lewis D. Counterfactuals. Cambridge Mass., 1973

[7] Putnam H. Meaning and Reference. - Journal of Philosophy, 1973, v.70. P. 707.

[8] Putnam H. Representation and Reality. Cambridge Mass., 1988.
[9] Quine W. V. Word and Object. Cambridge Mass. — N.Y., 1960.

[10] Victor Novoselov. Sign and Reality, Social Sciences. Vol. 1, No.1,2012,pp.1-6

http://www.sciencepublishinggroup.com/journal/archive.asp $\mathrm{x}$ ? journalid $=202$ \&issueid $=2020101$

[11] Victor Novoselov. The Problem of a Signs and World Objects Parity, International Journal of Economy, Management and Social Sciences, Vol 2 - No 12, 2013. pp. 1002-1007 : $\mathrm{http} / /$ tijournals.com/index.php?action $=$ showinpress\&jid $=6$ \&pid $=44$

[12] Victor Novoselov. Meaning, Interpretation and Unlimited Semiosis. Social Sciences. Vol. 3, No. 1, 2014, pp.5-8. http://www.sciencepublishinggroup.com/journal/paperinfo.a spx?journalid $=202 \&$ doi $=10.11648 /$ j.ss.20140301.12

[13] Victor Novoselov. Meaning and Interpretation in a Context of Semiotics. American Journal of Educational Research. 2014, 2(3),149-151.

http://www.sciepub.com/education/content/2/3\# 